\title{
Ion Synthesis: Si-Ge Quantum Dots
}

(C) N.N. Gerasimenko ${ }^{1}$, N.S. Balakleyskiy ${ }^{2,}$, A.D. Volokhovskiy ${ }^{3}$, D.I. Smirnov ${ }^{4}$, O.A. Zaporozhan ${ }^{1}$

${ }^{1}$ National Research University of Electronic Technology,

124498 Moscow, Russia

${ }^{2}$ Angstrrem,

124460 Moscow, Russia

${ }^{3}$ Angstrem-T,

124498 Moscow, Russia

${ }^{4}$ Lebedev Physical Institute of the Russian Academy of Sciences,

119333 Moscow,Russia

ๆ E-mail: balakleyskiy@gmail.com

We present a method of Si-Ge QDs formation by ion beam implantation (IBI) technique and high temperature annealing for self-organization. Implantation doses varied from $10^{14} \mathrm{~cm}^{-2}$ to $10^{17} \mathrm{~cm}^{-2}$, ion energies ranged from $50 \mathrm{keV}$ to $150 \mathrm{keV}$, annealing proceeded at temperature of $950^{\circ} \mathrm{C}$ to $1050^{\circ} \mathrm{C}$ in argon environment.Formed QDs show strong infrared (IR) photoluminescence (PL) in the temperature region $15-250 \mathrm{~K}$.

\section{Acknowledgements}

This work has been supported by the Russian Science Foundation (program 15-19-10054). 